\title{
Validation of the energy budget of an alpine snowpack simulated by several snow models (SnowMIP project)
}

\author{
Pierre ETChevers, ${ }^{1}$ Eric MARtin, ${ }^{1}$ Ross BrOWN,${ }^{2}$ Gharles FierZ, ${ }^{3}$ Yves Lejeune,${ }^{1}$ \\ Eric BAZILE, ${ }^{4}$ Aaron BOONE ${ }^{4}$ Yong-Jiu DAI,${ }^{5}$ Riahard ESSERY, ${ }^{6}$ Alberto FERNANDEZ, ${ }^{7}$ \\ Yeugeniy GUSEV, ${ }^{8}$ RaGhel JORDAN,${ }^{9}$ VIGTOR KOREN, ${ }^{10}$ Eva KOWALCZYK, ${ }^{11}$ \\ N. Olga NASONOVA, ${ }^{8}$ R. David PYLES, ${ }^{12}$ Adam SCHLOSSER, ${ }^{13}$ Andrey B. SHMAKIN, ${ }^{14}$ \\ Tatiana G. SMiRnOVA, ${ }^{15}$ Ulrigh STRASSER, ${ }^{16}$ Diana VERSEGHY, ${ }^{2}$ Takeshi YAMAZAKI, ${ }^{17}$ \\ ZONG-LiANG YANG ${ }^{18}$ \\ ${ }^{1}$ Centre d'Etudes de la Neige, Centre National de Recherches Météorologiques/Météo-France, 1441 rue de la Piscine, \\ 38406 Saint-Martin-d'Hères Cedex, France \\ E-mail:pierre.etchevers@meteo.fr \\ ${ }^{2}$ Climate Processes and Earth Observation Division, Meteorological Service of Canada, 2121 Trans-Canada Highway, Dorval, \\ Québec H9P173, Canada \\ ${ }^{3}$ WSL Swiss Federal Institute for Snow and Avalanche Research SLF, Flüelastrasse 11, CH-7260 Davos-Dorf, Switzerland \\ ${ }^{4}$ Météo-France Centre National de Recherches Météorologiques, 42 Avenue Coriolis, 31057 Toulouse Cedex, France \\ ${ }^{5}$ Institute of Atmospheric Physics, Chinese Academy of Sciences, Beijing 100029, China \\ ${ }^{6}$ Hadley Centre for Climate Prediction and Research, Meteorological Office, London Road, Bracknell, Berkshire RG12 2SZ, England \\ ${ }^{7}$ Instituto Nacional de Meteorología, Camino de las Moreras, s/n Cuidad Universitaria, 28040 Madrid, Spain \\ ${ }^{8}$ Laboratory of Soil Water Physics, Institute of Water Problems, Russian Academy of Sciences, 3 Gubkina Street, 117971 Moscow, Russia \\ ${ }^{9}$ U.S. Army Cold Regions Research and Engineering Laboratory, 72 Lyme Road, Hanover, NH 03755-1290, U.S.A. \\ ${ }^{10}$ NOAA/NWS/OH1/HRL, 1325 East-West Highway, Silver Spring, MD 20910, U.S.A. \\ ${ }^{11}$ CSIRO Atmospheric Research, Private Bag No. 1, Aspendale, Victoria 3195, Australia \\ ${ }^{12}$ Cooperative Institute for Research in the Environmental Sciences, University of Colorado, Boulder, CO 80309-0429, U.S.A. \\ ${ }^{13}$ COLA/IGES, 4041 Powder Mill Road, Suite 302, Calverton, MD 20705, U.S.A. \\ ${ }^{14}$ Laboratory of Climatology, Institute of Geography, Russian Academy of Sciences, 23 Staromonetny Street, 109017Moscow, Russia \\ ${ }^{15}$ Forecast Systems Laboratory, 325 Broadway, R/E/FS1 Boulder, CO 80303, U.S.A. \\ ${ }^{16}$ Department of Earth and Environmental Sciences, University of Munich, Luisenstrasse 37, D-80333 Munich, Germany \\ ${ }^{17}$ Frontier Observational Research System for Global Change, 3173-25, Showa-Machi, Kanazawa-ku, Yokohama 236-0001, Japan \\ ${ }^{18}$ Department of Hydrology and Water Resources, P.O. Box 210011, The University of Arizona, Tucson, AZ 85721-0011, U.S.A.
}

\begin{abstract}
Many snow models have been developed for various applications such as hydrology, global atmospheric circulation models and avalanche forecasting. The degree of complexity of these models is highly variable, ranging from simple index methods to multi-layer models that simulate snow-cover stratigraphy and texture. In the framework of the Snow Model Intercomparison Project (SnowMIP), 23 models were compared using observed meteorological parameters from two mountainous alpine sites. The analysis here focuses on validation of snow energy-budget simulations. Albedo and snow surface temperature observations allow identification of the more realistic simulations and quantification of errors for two components of the energy budget: the net short- and longwave radiation. In particular, the different albedo parameterizations are evaluated for different snowpack states (in winter and spring). Analysis of results during the melting period allows an investigation of the different ways of partitioning the energy fluxes and reveals the complex feedbacks which occur when simulating the snow energy budget. Particular attention is paid to the impact of model complexity on the energy-budget components. The model complexity has a major role for the net longwave radiation calculation, whereas the albedo parameterization is the most significant factor explaining the accuracy of the net shortwave radiation simulation.
\end{abstract}

\section{INTRODUCTION}

Over the last 30 years, many snow models have been developed and have been used for wide range of studies including hydrology, global circulation modelling, snow monitoring, snow physics and avalanche forecasting. The complexity of the models is highly variable, ranging from simple index methods to multi-layer models that simulate snow-cover stratigraphy and texture. Up to now, snow-cover models have only been subjected to limited comparisons, involving just a few models of various complexity (e.g. Essery and others, 1998; Jin and others, 1999; Boone and Etchevers, 
Table 1. Period of measurement of the snow surface and of the albedo and period of simulation by the models for the three seasons

\begin{tabular}{llll}
\hline & Snow surface temperature & Albedo & Simulated period \\
\hline CDP9697 & 19 Nov. 1996 to 16 Mar. 1997 & 19 Nov. 1996 to 27 Mar. 1997 & 6 Oct. 1996 to 10 Jun. 1997 \\
CDP9798 & 3 Dec. 1997 to 3 May 1998 & 1 Dec. 1997 to 1 May 1998 & 8 Oct. 1997 to 20 Jun. 1998 \\
WFJ9293 & 28 Oct. 1992 to 3 May 1993 & 22 Oct. 1992 to 26 Jun. 1993 & 1 Aug. 1992 to 31 Jul. 1993
\end{tabular}

2001), or the simulation of the mass balance of the snowpack by a large number of models for a Russian site (PILPS 2d; Schlosser and others, 2000) and for Swedish catchments (PILPS 2e; Bowling and others, 2003). These studies have established that processes internal to the snow cover are important for improved performance in most applications. It also appears that the model performance is very dependent on model application. In some cases, a very simple model is more appropriate than a sophisticated one (e.g. when input datasets are poor). Based on these studies, it appeared that a more general comparison of snow models was needed. This is why the Snow MIP project was begun a few years ago. The

Table 2. Participating models: the models are grouped according to complexity (from 1 for very simple models to 4 for very complex models). For each model, the main characteristics are indicated: Are several layers used to simulate the snowpack? Is an explicit soil model used? Are the turbulent exchange coefficient and the snow density variable? Is albedo a function of snow surface temperature, snow age and/or snow type? Is there liquid water storage in the snowpack?

\begin{tabular}{|c|c|c|c|c|c|c|c|c|c|c|}
\hline Model & $\begin{array}{l}\text { Model } \\
\text { acronym }\end{array}$ & Complexity & $\begin{array}{l}\text { Multi- } \\
\text { layer? }\end{array}$ & Soil model? & $\begin{array}{c}\text { Variable } \\
C_{\mathrm{H}} ?\end{array}$ & $\begin{array}{l}\text { Variable } \\
\text { density? }\end{array}$ & $\begin{array}{c}\text { Albedo } \\
f(\text { snow } \\
\text { surface } \\
\text { temperature) }\end{array}$ & $\begin{array}{l}\text { Albedo } \\
f(\text { age })\end{array}$ & $\begin{array}{c}\text { Albedo } \\
f(\text { snow } \\
\text { type })\end{array}$ & $\begin{array}{c}\text { Liquid } \\
\text { storage? }\end{array}$ \\
\hline
\end{tabular}

\begin{tabular}{|c|c|c|c|c|c|c|c|c|c|c|c|}
\hline SNOW-17 & SNO & 1 & No & No & No & Yes & No & No & No & Yes & Anderson (1973) \\
\hline SWAP $^{1}$ & SWA & 1 & No & Yes & Yes & Yes & No & No & No & Yes & Gusev and Nasonova (1998) \\
\hline CLASS $^{2}$ & CLA & 2 & No & Yes & Yes & Yes & No & Yes & No & No & Verseghy (1991) \\
\hline CLASS-NSD ${ }^{3}$ & CLD & 2 & No & Yes & Yes & Yes & No & Yes & No & No & Verseghy (1991) \\
\hline COLA-SsiB ${ }^{4}$ & $\mathrm{COL}$ & 2 & No & Yes & Yes & No & Yes & No & No & No & Xue and others (1991) \\
\hline ESCIMO $^{5}$ & ESC & 2 & No & No & No & No & No & Yes & No & No & Strasser and others (2002) \\
\hline INM SM $^{6}$ & INM & 2 & No & No & No & Yes & No & Yes & No & Yes & Fernández (1998) \\
\hline ISBA $^{7}$ & ISF & 2 & No & Yes & Yes & Yes & No & Yes & No & No & Douville and others (1995) \\
\hline $\mathrm{ISO}^{8}$ & ISO & 2 & No & Yes & Yes & No & No & Yes & No & No & Bazile and others (2002) \\
\hline $\operatorname{MOSES}^{9}$ & UKM & 2 & No & Yes & Yes & No & No & No & No & No & Cox and others (1999) \\
\hline NOAH-LSM ${ }^{10}$ & $\mathrm{NOH}$ & 2 & No & Yes & Yes & Yes & No & No & No & Yes & Koren and others (1999) \\
\hline SPONSOR & SPO & 2 & No & Yes & Yes & Yes & Yes & No & No & Yes & Shmakin (1998) \\
\hline TSCM $1^{11}$ & $\mathrm{TS} 1$ & 2 & No & No & No & No & Yes & Yes & No & Yes & Kondo and Yamazaki (1990) \\
\hline $\operatorname{ACASA}^{12}$ & ACA & 3 & Yes & Yes & Yes & Yes & Yes & No & No & No & Pyles and others (2000) \\
\hline CSIRO $^{13}$ & CSI & 3 & Yes & Yes & Yes & Yes & Yes & Yes & No & No & Kowalczyk (unpublished data) \\
\hline IAP94 $4^{14}$ & IAP & 3 & Yes & Yes & No & Yes & No & Yes & No & Yes & Dai and Zeng (1997) \\
\hline ISBA-ES ${ }^{15}$ & ISB & 3 & Yes & Yes & Yes & Yes & No & Yes & No & Yes & Boone and Etchevers (2001) \\
\hline MAPS $^{16}$ & MAP & 3 & Yes & Yes & Yes & Yes & No & No & No & No & Smirnova and others (2000) \\
\hline MATSIRO & MAT & 3 & Yes & Yes & Yes & No & Yes & Yes & No & No & Takata and Emori (1999) \\
\hline TSCM & TSM & 3 & Yes & Yes & No & Yes & Yes & Yes & No & Yes & Yamazaki (2001) \\
\hline VISA $^{17}$ & VIS & 3 & Yes & Yes & Yes & Yes & No & Yes & No & Yes & $\begin{array}{l}\text { Niu and Yang (2003); Yang and } \\
\text { Niu (2003) }\end{array}$ \\
\hline Crocus & CRO & 4 & Yes & No & Yes & Yes & No & Yes & Yes & Yes & Brun and others (1989) \\
\hline SNOWPACK & $\mathrm{SNO}$ & 4 & Yes & Yes & Yes & Yes & Yes & No & Yes & Yes & $\begin{array}{l}\text { Bartelt and Lehning (2002); } \\
\text { Lehning and others }(2002 a, b)\end{array}$ \\
\hline SNTHERM & SNT & 4 & Yes & Yes & Yes & Yes & No & No & Yes & Yes & Jordan (1991) \\
\hline
\end{tabular}

\footnotetext{
${ }^{1}$ South West Asia Project. ${ }^{2}$ Canadian Land Surface Scheme. ${ }^{3}$ New Snow Density. ${ }^{4}$ Center for Ocean-Land Atmospheric Studies - Simplified Simple Biosphere. ${ }^{5}$ Energy Balance Snow Cover Integrated Model. ${ }^{6}$ Instituto Nacional de Meteorología (Spain) Snow Model. ${ }^{7}$ Interactions Soil-Atmosphere-Biosphere. ${ }^{8}$ Inflow-Storage-Outflow. ${ }^{9}$ Meteorological Office Surface Exchange Scheme. ${ }^{10}$ Nitrous Oxide and Halocompounds Group Land Surface Model. ${ }^{11}$ Tohuku Snow Cover Model (TSCM) with One layer. ${ }^{12}$ Advanced Canopy-Atmosphere-Soil Algorithm. ${ }^{13}$ Commonwealth Scientific and Industrial Research Organisation. ${ }^{14}$ Institute of Atmospheric Physics (Academy of Sciences, China). ${ }^{15}$ ISBA — Explicit Snow. ${ }^{16}$ Mesoscale Analysis and Prediction System. ${ }^{17}$ Versatile Integrator of Snow Atmosphere Processes.
} 
project objectives, the methodology and some results concerning snow water equivalent and snow-cover duration have already been presented by Etchevers and others (2002). This paper focuses on the simulation of the snow energy budget and the partition of the energy fluxes into long- and shortwave radiation and turbulent fluxes. The study has two objectives:

to compare the uncertainty in the calculation of each of the energy-budget components by model, and

to bring to light the role of model complexity and the impact of different parameterizations on the energybudget simulation.

Section 2 below explains the nature of the intercomparison and briefly describes the participating models. Section 3 describes the validation of the energy-budget simulation by comparison with observations. Using radiation measurements, the simulation of two of the three main components of the energy budget can be validated: the short- and longwave net radiation. In section 4, a discussion concerning the simulation of the third component (the turbulent fluxes) is presented.

\section{EXPERIMENT PRINGIPLES}

\subsection{Atmospheric forcing and validation datasets}

Complete datasets on snowpacks including albedo and snow surface temperature for a long period (several months) are rare because they require great human and technical resources. Of the four Snow MIP reference sites, albedo and snow surface temperature measurements are available for a whole winter only for Col de Porte (CDP) and Weissfluhjoch (WFJ), both in the Alps. Hence, the comparison is unfortunately limited to alpine sites, situated at relatively high altitudes. Future measurement campaigns are needed to complete the model validation data over a wider range of snow types.

CDP is a middle-elevation site located in the French Alps $\left(45.3^{\circ} \mathrm{N}, 5.77^{\circ} \mathrm{E} ; 1340 \mathrm{~m}\right.$ a.s.l.). The air temperature, even in mid-winter, is often close to freezing, and the site is not windy (monthly average wind speed $<1 \mathrm{~m} \mathrm{~s}^{-1}$ ). Rainfall and snowmelt can occur at any time during the winter, and the relative humidity is high (average $70-90 \%$ ). WFJ is a more mountainous site that lies at $2540 \mathrm{~m}$ a.s.l. in the Swiss Alps $\left(46.83^{\circ} \mathrm{N}, 9.81^{\circ} \mathrm{E}\right)$. Winter air temperature is lower (monthly average $267-271 \mathrm{~K}$, October-April) and rain does not occur before May. The site is windy $\left(2 \mathrm{~m} \mathrm{~s}^{-1}\right.$ on average) and there is little drifting. The air is dry since the monthly relative humidity is $<60 \%$. For both sites, meteorological surface parameters were measured every hour: precipitation amount, air temperature, humidity and wind speed were measured $2 \mathrm{~m}$ above the snow surface; long- and shortwave incoming radiation were measured $2 \mathrm{~m}$ above the snow at CDP and $5 \mathrm{~m}$ above the snow at WFJ. The precipitation phase (rain or snow) was estimated from parameters such as air temperature and accumulation in non-heated rain gauges. Snowpack data are also available, with a frequency depending on the measurement type (hourly for albedo and surface temperature, weekly for snow pits) for both sites. Two winters were simulated for CDP (referred to as CDP9697 and CDP9798) and one for WFJ (referred to as
WFJ9293); the simulated periods are given for each site in Table 1.

\subsection{Simulation experiments}

The simulations are "stand-alone", meaning that the meteorological parameters are prescribed every hour and the models calculate the snowpack evolution. The snowpack data were not made available to the participants (no calibration was possible) and are used for validation purposes. Twenty-three snow models participated in the project. These were developed for a wide range of applications and exhibit a large range of complexity. Table 2 presents the models, the main parameterizations they use for surface mass and energy exchanges, and the internal processes and numbers of layers they simulate. The models are grouped according to complexity. The model complexity is difficult to define because it depends on many factors and there is no objective method to estimate it. In this paper, it is assumed to be equal to 1 for very simple models (using one snow layer and a very simple snow energy budget), 2 for simple models (using one snow layer and a detailed snow energy budget), 3 for complex models (using two or more snow layers) and 4 for very complex models that include the internal physical processes of the snowpack. Following this classification, 2 models (out of 23) can be considered as very simple, 10 as simple, 8 as complex and 3 as very complex.

\section{SNOW ENERGY-BUDGET GOMPONENT VALIDATION}

The snowpack energy budget is governed by fluxes exchanged between the snow, atmosphere and the soil. In an alpine environment, soil/snowpack energy transfers are generally weak when compared with atmosphere/snow ones. In eight models the ground heat flux is fixed at a constant value, and in 15 models it is calculated by the model itself. Two runs (with or without an explicit simulation of the soil) were provided by some models (3 out of 23), but the results do not differ greatly as a consequence. This paper focuses on the exchange between the atmosphere and the snowpack.

The snow energy budget (SEB) can be written as

$$
\mathrm{SEB}=\mathrm{LW}_{\text {net }}+\mathrm{SW}_{\text {net }}+H+\mathrm{LE}+Q \text {, }
$$

where the fluxes are defined as positive when they are oriented towards the snowpack (i.e. when energy is gained by the snowpack). $\mathrm{LW}_{\text {net }}$ and $\mathrm{SW}_{\text {net }}$ are the net long- and shortwave radiation, and $H$ and LE are the turbulent sensible- and latent-heat fluxes. $Q$ includes all other surface fluxes (at the snow/soil interface and energy advected by precipitation), which are generally negligible for the alpine seasonal snowpacks simulated here. For CDP, rainfall occurs even in mid-winter and can bring a bit more residual energy to the snowpack than in WFJ, but the advected energy represents only a few per cent of the net radiation.

The SEB plays a major role in snowpack modelling because it governs the snow evolution (melting, cooling, sublimation, etc.). In particular, the energy partition between radiation and turbulent fluxes can vary from one site to another, and models should be able to simulate different partitioning induced by different climatic environments. The validation data collected for the SnowMIP project allow a partial validation of this flux partition, since albedo 


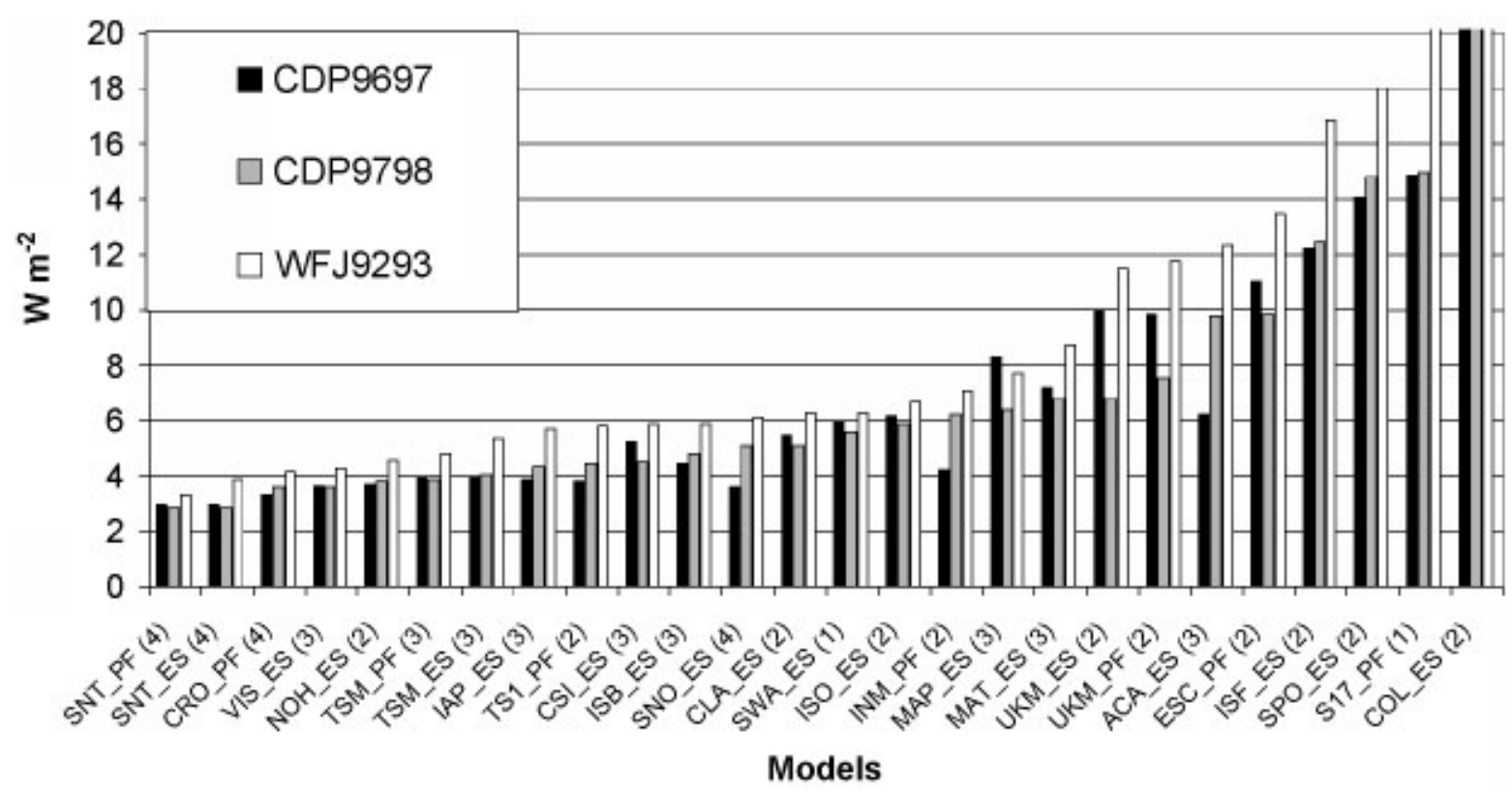

Fig. 1. Daily rms error in net longwave radiation calculated for the three seasons and for each model. The type of simulated soilsnow exchange is indicated by the two letters following the model acronym: PF (prescribed flux) or ES (explicit soil). The number in parentheses corresponds to the model complexity (as given by Table 2).

and snow surface temperatures were measured at GDP and WFJ.

\subsection{Longwave radiation flux}

The net longwave radiation flux is the difference between longwave radiation from the atmosphere and that emitted by the snow. As the incoming flux is provided to the snow models as input data, differences in the longwave radiation budget are due to the emitted longwave radiation. This flux ( $\left.\mathrm{LW}_{\text {emitted }}\right)$ is calculated by the models as a function of the snow surface temperature $\mathrm{T}_{\text {sim }}$ by

$$
\mathrm{LW}_{\text {emitted }}=\varepsilon \sigma T_{\mathrm{sim}}^{4},
$$

where $\sigma$ is the Boltzmann constant and $\varepsilon$ is the snow emissivity used by the model.

One practical way to validate this flux is to compare the observed and simulated net longwave radiation. The daily bias and root-mean-square (rms) error have been calculated for the measurement periods given in Table 1. For a given model, the bias is very different from one site to another: no systematic error (overestimation or underestimation) is noticeable. Six models succeed in calculating the net longwave radiation with a bias which ranges from -3 to $3 \mathrm{~W} \mathrm{~m}^{-2}$ for both sites (which is approximately equivalent to a snow surface temperature bias of -0.7 to $0.7 \mathrm{~K}$ ). The rms error varies between 3 and $6 \mathrm{~W} \mathrm{~m}^{-2}(0.7-1.5 \mathrm{~K}$ for snow surface temperature) for these six models, and from 6 to $12 \mathrm{~W} \mathrm{~m}^{-2}$ for most of the other models $(1.5-3 \mathrm{~K}$ for snow surface temperature) (Fig. 1). On average for all the models (except the three least accurate), the rms error reaches $5.7 \mathrm{~W} \mathrm{~m}^{-2}$ for CDP9697 and CDP9798 and $7.3 \mathrm{~W} \mathrm{~m}^{-2}$ for WFJ.

For WFJ, the snowpack remained cool during the whole season and the surface temperature decreased far below 273.15 K (257.6 K for the last 10 days of December; $253 \mathrm{~K}$ for the last 10 days of February). These large variations of temperature (and emitted longwave radiation) are difficult to simulate because they require correctly integrating the surface energy budget over a long time, since errors accumulate. Hence, the larger errors occur for WFJ (Fig. 1). Note that the rms error does not include the melting period (May-June 1993), because the data are available only until the beginning of May 1993. In contrast, the CDP climate is more temperate and rainfall or surface snowmelt can occur in mid-winter. Consequently, the surface temperature is often close to $273.15 \mathrm{~K}$ and cannot drop much. The models are more successful in calculating the surface temperature as soon as they correctly calculate the melting events.

As indicated in Figure 1, the most complex models generally had the lowest longwave-radiation rms errors: the average rms error for the three simulation winters is equal to $1.4 \mathrm{~W} \mathrm{~m}^{-2}$ for the very complex models (level 4), $2.0 \mathrm{~W} \mathrm{~m}^{-2}$ for the complex models (level 3) and $4.1 \mathrm{~W} \mathrm{~m}^{-2}$ for the simplest models (levels 2 and 1). This shows that the net longwave radiation is a good integrator of the complex interactions which occur in the snowpack, and that the accuracy in its calculation is closely linked to model capacity to simulate general snowpack features, at least during the accumulation period.

\subsection{Shortwave radiation flux}

As for longwave radiation flux, the incoming shortwave radiation is the same for all the models, and the shortwave radiation budget simulation depends on the fraction of the radiation which is reflected by the snowpack, i.e. the snow albedo. The albedo parameterizations of the 23 models are based on temperature (6 models), snow type and/or grainsize (6 models) or snow age (13 models). Four models use either no albedo or a fixed albedo (index-based, constant or depending only on vegetation fraction or shading). Some models use two parameterizations (e.g. age can account for all the aging processes of snow or can be used in conjunction with a parameterization based on snow-grain size or type (Table 2)). 


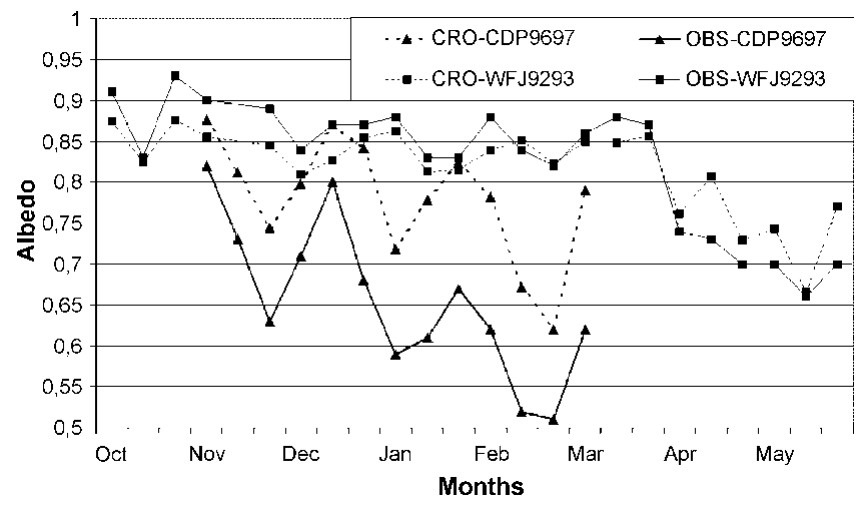

Fig. 2. Ten-day averaged albedo observed (solid lines) and simulated by the snow model Crocus (dashed lines) for CDP (triangles) and WFJ (squares).

\subsubsection{Weissfluhjoch}

The simulation results are very sensitive to albedo parameterization during spring, when the shortwave radiation budget becomes dominant. At WFJ, the onset of surface snowmelt is around mid-April, and significant runoff is observed after the end of April. During the snowmelt period, the observed albedo decreases, with large variations due to frequent snowfalls. These variations are difficult to simulate, although the general trend is well captured by the models. The period 20-30 April (a relatively long dry period) shows how parameterizations based only on age can be inaccurate. During periods like this, parameterizations based on grain-size give better simulations of albedo. Another discrepancy that appeared in the WFJ simulations is related to the sensitivity of albedo to surface grain-size or type. Some of the models overestimate the albedo increase due to small snowfalls when, in fact, the surface layer is so thin that the albedo is also affected by the underlying snow.

\subsubsection{Col de Porte}

At CDP, the albedo measurement is more difficult to compare with model results than at WFJ because the snowpack contains tree litter and atmospheric dust that is not explicitly taken into account by the snow models. Thus the observed values of albedo are low when compared with model simulations (which calculate the albedo of clean snow). Figure 2 shows the observed albedo compared with the albedo simulated by the Crocus model for CDP and WFJ. One should note that the Crocus albedo parameterization is based on laboratory experiment results (Brun and others, 1992) and is independent of the field measurement at CDP or WFJ. The simulated albedo is close to observations for WFJ (where the snow is clean), but it is about $15 \%$ higher than observed for CDP.

Albedo variations seem to be less influenced by the impurities present in the snowpack, so it is interesting to compare the simulated albedo variations with the observed a

\section{CDP9798: daily albedo}
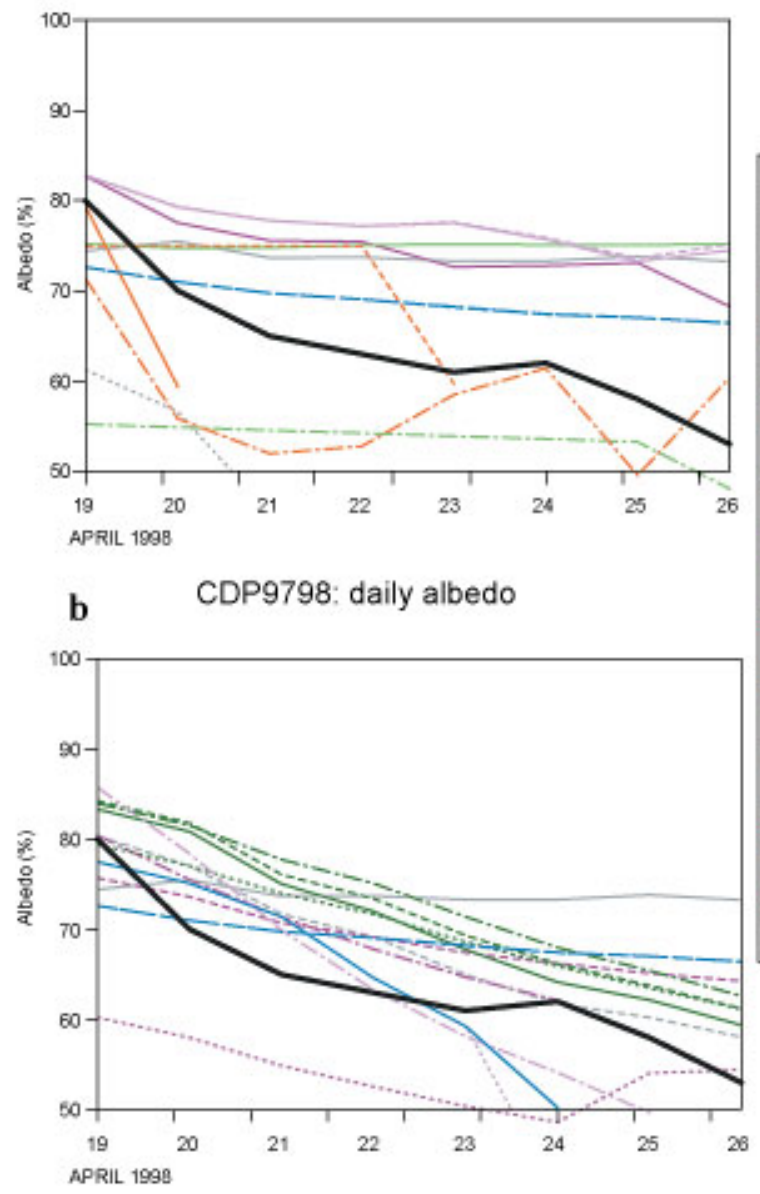

c

WFJ9293: daily albedo

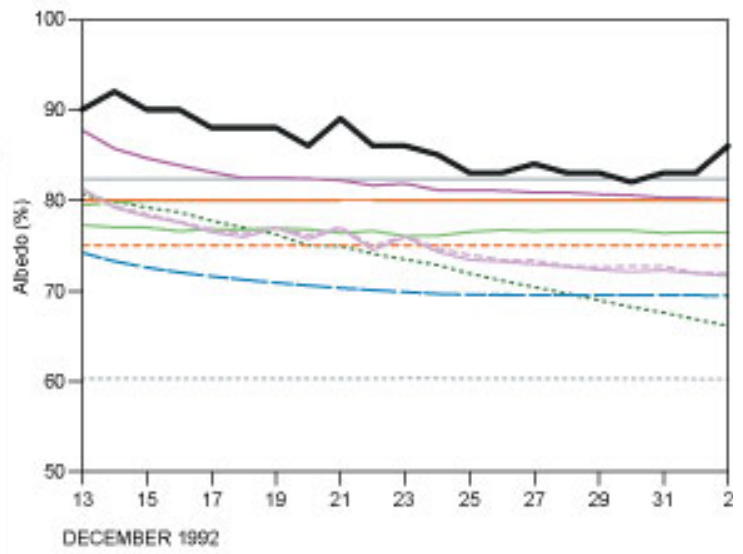

WFJ9293: daily albedo

d

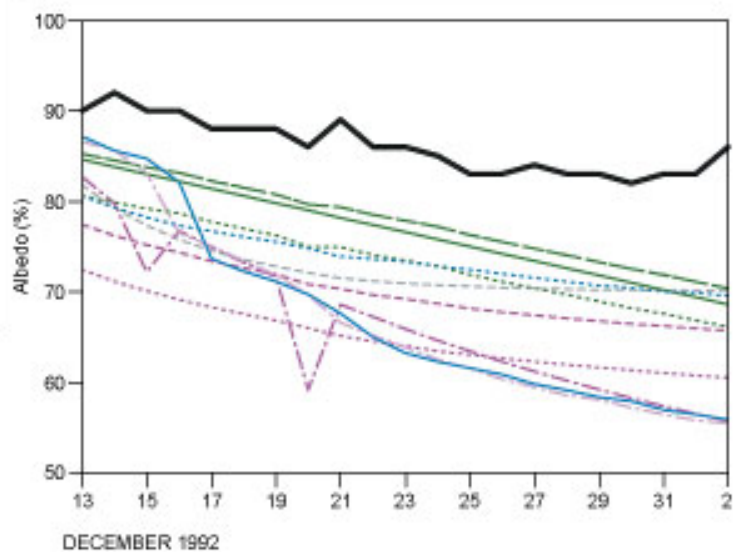

Fig. 3. Daily albedo observed (thick black line) for ( $a, b$ ) episode 3 (CDP site, 19-25 April 1998) and (c, d) episode 4 (WFJ site, 13 December 1992 to 2 January 1993) (see the episode definitions in Table 3). The other coloured lines represent the albedo simulations: $(a)$ and (c) correspond to models using an albedo parameterization based on snow surface temperature and/or snow type or a constant albedo, and $(b)$ and $(d)$ to models using an albedo parameterization based on snow age. 


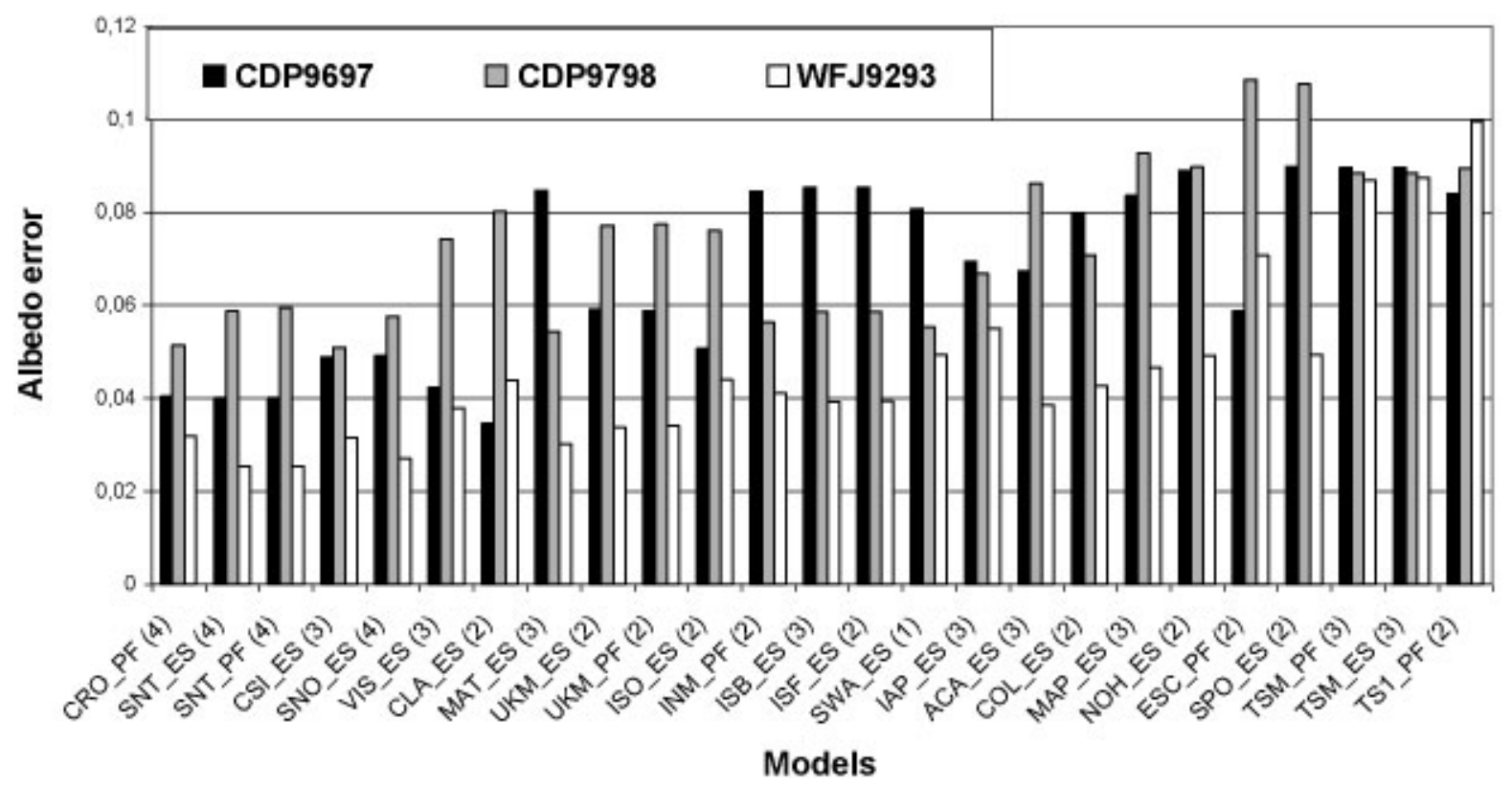

Fig. 4. Rms error in 10 day averaged snow albedo variations calculated for the three seasons and for each model. The type of simulated soil-snow exchange is indicated by the two letters following the model acronym: PF (prescribed flux) or ES (explicit soil). The number in parentheses corresponds to the model complexity (as given by Table 2).

ones. Out of 23 models, 8 manage to simulate the daily albedo variations with a rms error lower than $7 \% \mathrm{~d}^{-1}$ for the three sites, whereas the rms error is $7-10 \% \mathrm{~d}^{-1}$ for the other models. These rms errors are lower by about $35 \%$ at WFJ because the albedo stays very high (frequent snowfalls) and does not vary much in winter (no melt before the end of May).

\subsubsection{Some particular periods}

Increases in albedo are generally caused by snowfall, as the maximum albedo is generally associated with fresh snow. Decreases in albedo are more complex because they depend on the snow microstructure, grain type and impurity content. As stated above, the decrease of albedo is generally calculated by the models as a function of the snow age, surface temperature, grain-size and other parameters provided by the models themselves. These parameterizations play a major role in the model performances because albedo is a key factor for calculating the snowmelt. Thus, it is interesting to examine the accuracy of these parameterizations for a few particular periods. These selected periods cover at least 8 days and do not include snowfall events (Table 1). The three CDP periods correspond to snowmelt events, and the albedo decrease $\left(-1.63 \% \mathrm{~d}^{-1}\right.$ on average $)$ is due to the appearance of liquid water in the snowpack. At WFJ, the decrease is five times weaker $\left(-0.32 \% \mathrm{~d}^{-1}\right.$ on average $)$ because it is the result of dry-snow evolution (without melting or rain). The quality of each simulation is determined by comparing the change in observed and simulated albedos between the beginning and end of each period. The albedo decrease averaged for all models is pretty accurate for all the episodes (Table 3), but the extreme values show that some models drift far from reality. For the six episodes, the rms error of the albedo variation is $7-13 \%$, but average results are very different for the two sites. The rms error is generally larger for the CDP site $(8-16 \%)$ than for the WFJ site $(3-11 \%)$.

The performance of a given model is highly dependent on its albedo parameterization. For the CDP site, the models which best simulate the snow albedo use parameterizations based on the snow age and/or the snow type. Because the albedo regularly decreases during the episodes, the age parameterization is adequate to correctly simulate this evolution. This is illustrated by Figure $3 a$ and b, where the daily simulated and observed albedos are plotted for episode 3 (CDP9798). The results plotted in Figure 3a and c correspond to models using an albedo parameterization based on the snow surface temperature, the snow type or a constant albedo. In Figure $3 \mathrm{~b}$ and $\mathrm{d}$, the results come from models using an albedo parameterization depending on snow age. For CDP, one can notice that the

Table 3. The six periods selected to validate albedo decreases. No precipitation occurred occurred during these episodes. The last two columns contain the average for all models and the minimum/maximum values of the simulated albedo variations

\begin{tabular}{|c|c|c|c|c|c|c|c|}
\hline Episode & Site & Period & Number of days & $\begin{array}{c}\text { Observed albedo } \\
\text { (beginning and end) }\end{array}$ & $\begin{array}{l}\text { Observed albedo } \\
\text { variation } \\
\text { (perday) }\end{array}$ & $\begin{array}{l}\text { Simulated albedo } \\
\text { variations: average } \\
\text { (perday) }\end{array}$ & $\begin{array}{c}\text { Simulated albedo } \\
\text { variations: min.-max. } \\
\text { (per day) }\end{array}$ \\
\hline 1 & CDP96 97 & 28 Feb. 1997 to 14 Mar. 1997 & 15 & $0.63-0.5$ & -0.0087 & -0.01 & $-0.02-0.005$ \\
\hline 2 & CDP97 98 & 24 Jan. 1998 to 20 Feb. 1998 & 28 & $0.77-0.59$ & -0.0064 & -0.006 & $-0.01-0.001$ \\
\hline 3 & CDP97 98 & 19 Apr. 1998 to 26 Apr. 1998 & 8 & $0.8-0.53$ & -0.0338 & -0.015 & $-0.03-0.00$ \\
\hline 4 & WFJ & 13 Dec. 1992 to 2 Jan. 1993 & 21 & $0.9-0.86$ & -0.0019 & -0.005 & $-0.01-0.005$ \\
\hline 5 & WFJ & 29 Jan. 1993 to 14 Feb. 1993 & 17 & $0.91-0.8$ & -0.0065 & -0.008 & $-0.02-0.00$ \\
\hline 6 & WFJ & 21 Apr. 1993 to 29 Apr. 1993 & 9 & $0.75-0.74$ & -0.0011 & -0.009 & $-0.03-0.009$ \\
\hline
\end{tabular}




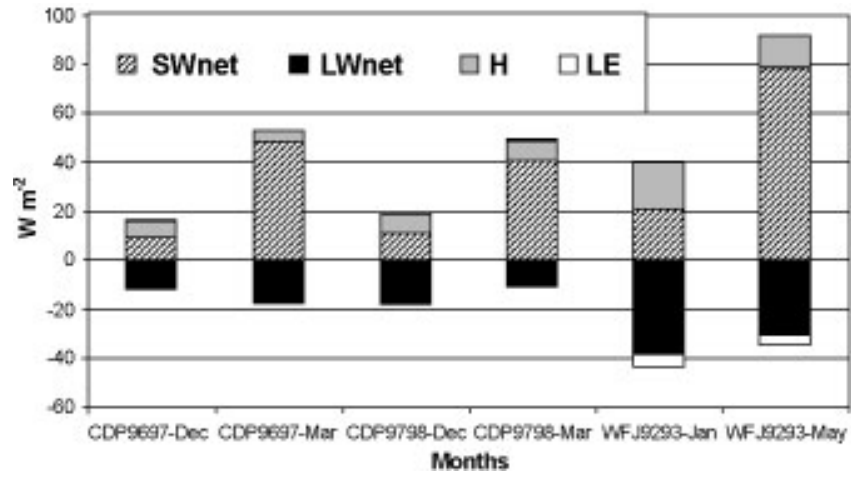

Fig. 5. Monthly components of the surface energy budget (on average for all the models). For each season, a winter and a spring month are presented.

model results shown in Figure $3 \mathrm{~b}$ properly reproduce the drop in albedo from 0.8 to 0.65 . In Figure $3 \mathrm{a}$, the albedo decrease is correctly calculated by the models using a snow-type parameterization and is underestimated by those using a parameterization based on snow surface temperature. As the snow surface stays close to $273 \mathrm{~K}$ during the melting period, it is not an accurate predictor. For the WFJ site, the decrease in albedo is very slow because the snow grain-size and type do not evolve very fast (no rain or melt). As shown by Figure $3 \mathrm{c}$ and d (which present episode 4), the most accurate models (Fig. 3c) use either a parameterization based on the snow type or a constant albedo (which is a pretty good approximation of the reality). The less accurate models use an age-based parameterization which overestimates the albedo decrease with time (Fig. 3d). Finally, if one considers the whole set of episodes, the models that best simulate the albedo variations appear to be the very complex ones. Indeed, three of the four most accurate models use albedo parameterizations based on snow grain characteristics and snow age. They are able to simulate both the slow albedo decrease in winter and the fast decrease during the melting period. The other models can usually properly simulate the albedo for one type of episode but not the other.

As shown by Figure 4, the 10 day averaged albedo variation rms error calculated for all three seasons is low for the very complex models. However, the complexity does not play a major role, and the model results are equivalent for complex and simple models. Hence, in the case of the albedo simulation, the relevant model characteristic appears not to be the model complexity, but the type of albedo parameterization used.

\subsubsection{Shortwave-radiation rms error}

The rms error of the net shortwave radiation for each model calculated using the observed albedo ranges from 12 to $22 \mathrm{~W} \mathrm{~m}^{-2}$ (average for the three sites, during the measurement periods given by Table 1). The values are larger for the WFJ site ( $r m s$ error $=18.5 \mathrm{~W} \mathrm{~m}^{-2}$ on average for all the models) than for the CDP site (about $11 \mathrm{~W} \mathrm{~m}^{-2}$ ). This difference is opposite to what we observed for albedo error, which is lower on average for WFJ. The reason for the difference is that the incoming shortwave radiation is greater at WFJ than at CDP because the melting occurs later in the season (beginning of June) and because of the higher elevation of WFJ. Thus a small error in the albedo at WFJ can produce relatively high errors in the absorbed shortwave radiation.
Finally, one should not forget that the albedo measurement for CDP has a bias due to the snowpack impurities, and the true net shortwave radiation $\mathrm{rms}$ error is probably lower than presented here.

\subsection{Turbulent fluxes}

Turbulent fluxes are the third main component of the snow energy budget. They can be quite variable and their average value is smaller than that of the radiative component budget, but in some particular cases they can play a major role (i.e. when the wind speed is strong and the air temperature high). Nevertheless, they are difficult to measure and no reliable direct observation is available for the Snow MIP validation sites. In the models, turbulent fluxes are parameterized as functions of meteorological parameters such as air temperature, wind speed and air humidity. The main difficulty lies in estimating the exchange coefficients which control the fluxes as function of the vertical air temperature and humidity gradients. In some models (17 out of 23), the exchange coefficient is variable, whereas it is constant for the others (Table 2).

Figure 5 presents the components of the snow energy budget at each site for a typical month of the accumulation period (winter) and for the melting period (spring), averaged for all the models which calculate these fluxes (16 out of 23 models). For CDP, the sensible-heat flux $(H)$ is always weak $\left(<9 \mathrm{~W} \mathrm{~m}^{-2}\right)$ and the latent-heat flux $(\mathrm{LE})$ is close to zero. For WFJ, the relatively strong wind increases the turbulent heat flux: the sensible-heat flux is doubled (due to the cooling of snow by radiative effects) and the latent-heat flux reaches $-5 \mathrm{~W} \mathrm{~m}^{-2}$ (as sublimation is favoured by the low humidity). The standard deviation calculated for all the models is very high and has the same magnitude as the average fluxes themselves.

One can notice that for the two sites the fraction of energy input to the snow by turbulent heat fluxes is always higher in winter than in spring. This can be estimated by calculating the ratio

$$
r_{\mathrm{SW}}=\frac{\mathrm{SW}_{\text {net }}}{|H|+\mathrm{SW}_{\text {net }}} .
$$

When $r_{\mathrm{SW}}$ is high, the net shortwave radiation plays the major role, whereas values of $r_{\mathrm{SW}}$ lower than 0.5 show that there is a significant contribution from sensible-heat fluxes. In winter, $r_{\mathrm{SW}}$ ranges from 0.5 to 0.6 (on average for all the models): the net shortwave radiation is quite low because of the weak incoming radiation and the high snow albedo. Moreover, the snowpack loses energy by longwave radiation and its surface temperature decreases, increasing the sensible heat-flux. In spring, $r_{\mathrm{SW}}$ increases to values of $0.8-$ 0.88 due to the increasing incoming shortwave radiation and the decreased albedo. At the same time, the sensibleheat flux tends to decrease as the difference between the snow and air temperatures diminishes (and as the wind also diminishes in spring for WFJ).

\section{DISGUSSION}

As indicated before, the turbulent-flux calculation cannot be validated because of the lack of reliable measurements. If a model simulates these fluxes far from reality, it can lead to errors in the overall snowpack simulation, such as incorrect surface temperatures in winter or incorrect melting 
rates in spring. In some cases, errors in turbulent fluxes can be compensated by errors in simulations of other physical processes. For instance, too low a sensible-heat flux in winter will decrease the energy gained by the snowpack, and the simulated snow surface temperature will drop too much. This will reduce the emitted longwave radiation, reducing radiative cooling which will partially compensate the lack of energy due to an underestimation of the sensible-heat flux. Such a compensation probably occurs in some simulations of the CDP and WFJ snowpacks, but it is not easy to identify the origin of a surface temperature error. During the melting period, an error in the turbulent fluxes can be more easily detected because it will directly impact the melting rate (assuming the other energy-budget components are correct). An example is shown in Figure 6, where the three main components of the energy budget and the corresponding melting amount are plotted for WFJ, for the period 24 May-9 June 1993. The first column of the histogram presents the observed fluxes: the net shortwave radiation is obtained from hourly measurement, and the melting amount is calculated from two pits dug on the first and last days of the period. As the net longwave radiation was not measured during this period, it was estimated assuming a constant snow surface temperature equal to $273.15 \mathrm{~K}$.

In order to compare the model results with the observed values, the models producing results closest to the observations were selected. Seven models do not calculate an energy budget, or provide an energy budget that is inconsistent with the simulated melting amount (however, one should keep in mind that the models ran in March 2001 and that they have surely been improved since this date). Among the other models, seven accurately simulate the snowmelt amount and/or the net short-wave radiation (Fig. 6). Five of them (models ESCIMO, Crocus, SNOWTHERM, SWAP and INM_SM) calculate the melting amount with reasonable accuracy (error $<15 \%$ ). These five models underestimate the shortwave radiation budget (by $8-26 \%$ ) and seem to compensate this energy loss by overestimating the turbulent sensible flux (which ranges from 21.8 to $38.1 \mathrm{Wm}^{-2}$ ). The two other models (UKM and CSIRO) underestimate the melt by $18-32 \%$, but their calculation of the shortwave radiation budget is pretty accurate $(-11 \%$ and $+1 \%)$. In these cases, the snow energy budget is too low because they probably underestimate the turbulent fluxes (by 12 and $3.1 \mathrm{~W} \mathrm{~m}^{-2}$ ). Since no model reproduces both the melting amount and the net shortwave radiation with a high enough accuracy, it is not possible to determine which simulated turbulent fluxes are the most realistic. Moreover, the differences between the models are of the same magnitude as the uncertainty in the estimated values of the turbulent fluxes: even if the general measurement quality for the WFJ site is high (uncertainty $<5 \%$ ), the estimated uncertainty in the turbulent fluxes due to the different assumptions reaches $10-20 \mathrm{~W} \mathrm{~m}^{-2}$, i.e. the same order of magnitude as the fluxes themselves.

\section{GONGLUSION}

The snowpack energy budget was simulated by 23 snow models in the Snow MIP project. Daily averages of snow albedo and surface temperature measurements are used to validate the model results. The net longwave radiation is

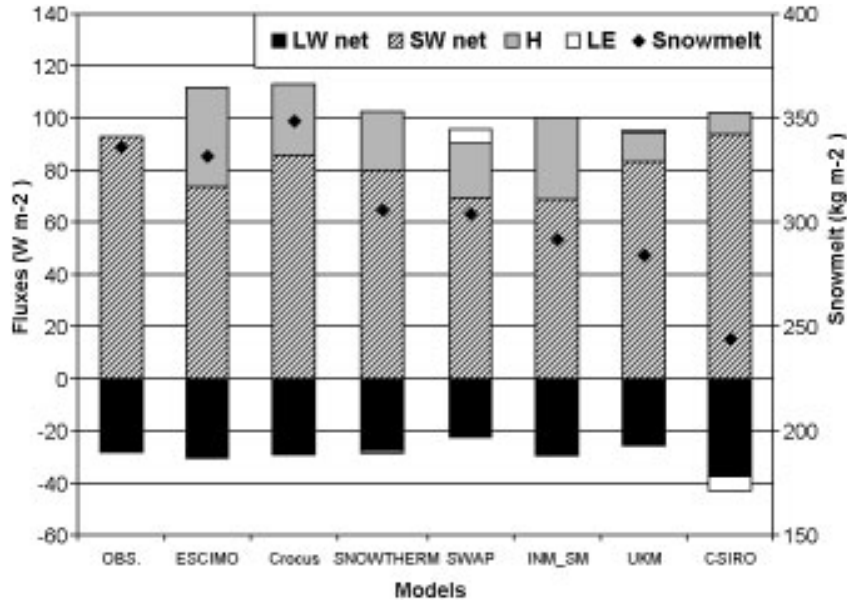

Fig. 6. Components of the surface energy budgets (histograms) and mass variation (diamonds) averaged for the WFJ site between 24 May 1992 and 9 June 1993. Each column corresponds to a model, selected for its accuracy in simulating the melt and/or the net shortwave radiation. The first column presents the observations (melt and net short-and longwave radiation only).

simulated with an rms error of $5-10 \mathrm{~W} \mathrm{~m}^{-2}$ on average for all the models. The net shortwave radiation is simulated with a slightly larger $\mathrm{rms}$ error $\left(10-20 \mathrm{~W} \mathrm{~m}^{-2}\right)$, due to the large values of the incoming radiation in the melting period (for WFJ) or to the effect of snow impurities on albedo (for CDP), a factor that is not computed by the models. When one selects some particular periods during which there was no precipitation, one can classify the models into three families: models using an albedo parameterization based on the snow age (accurate for melting periods); models using a surface-temperature-based parameterization or a constant value of albedo (which are accurate for non-melting periods); and models using a more complex parameterization based on snow type and grains (which generally simulate the differing albedo decrease rates well). The third main component of the snow energy budget, turbulent fluxes, cannot be directly validated by observation. On average, they do not play a significant role during the melting period (representing $<20 \%$ of the net shortwave radiation in spring), but they are non-negligible for some time periods. For instance, when one considers the WFJ snowpack from 24 May to 9 June 1993, one can remark that all the models which correctly simulate the melting amount underestimate the net shortwave radiation and compensate this default by simulating turbulent fluxes ranging from 27 to $38 \mathrm{~W} \mathrm{~m}^{-2}$. In contrast, the two models which simulate the net shortwave radiation well calculate lower values of the turbulent fluxes $\left(9\right.$ and $11 \mathrm{~W} \mathrm{~m}^{-2}$ ) and, consequently, produce a simulated amount of melting that is too small. Finally, the model complexity appears to have a strong impact on the net longwave radiation simulation. Indeed, snow surface temperature is the result of a complex equilibrium in the snowpack, and the models which explicitly simulate internal snow processes simulate the snow surface temperature best. In contrast, model complexity has relatively little impact on the albedo simulation. The very complex models reproduce albedo variations well because they explicitly calculate the dependence of albedo on the snow grains, but the simpler models can also simulate the albedo correctly if they use an appropriate albedo parameterization. 


\section{ACKNOWLEDGEMENTS}

The authors would like to thank the two anonymous reviewers and M. Sturm (Scientific Editor), who contributed to the improvement of this paper. Part of this work was supported by the Programme National de Recherches Hydrologiques, France, and the International Association of Hydrological Sciences/International Commission on Snow and Ice.

\section{REFERENCES}

Anderson, E. A. 1973. National Weather Service River Forecast System - snow accumulation and ablation model. Silver Spring, MD, U.S. Department of Commerce. (NOAA Technical Memorandum NWS Hydro-17.)

Bartelt, P. and M. Lehning. 2002. A physical SNOWPACK model for the Swiss avalanche warning. Part I. Numerical model. Cold Reg. Sci. Technol., 35(3), 123-145.

Bazile, E., M. El Haiti, A. Bogatchev and V. Spiridonov. 2002. Improvement of the snow parameterization in ARPEGE/ALADIN. Proceedings of SRNWP/HIRLAM workshop on snow processes, turbulence and Moutain effects, Madrid 22-24 October 2001, 14-19.

Boone, A. and P. Etchevers. 2001. An intercomparison of three snow schemes of varying complexity coupled to the same land-surface model: local scale evaluation at an Alpine site. 7. Hydrometeorol., 2, 374-394.

Bowling, L. C. and 23 others. 2003. Simulation of high latitude hydrological processes in the Torne-Kalix basin: PILPS Phase 2e. 1: experimental design and summary intercomparison. Global Planet. Change, 38 (1-2), 1-222.

Brun, E., E. Martin, V. Simon, C. Gendre and C. Coléou. 1989. An energy and mass model of snow cover suitable for operational avalanche forecasting. 7. Glaciol., 35(121), 333-342.

Cox, P. M., R. A. Betts, C. B. Bunton, R. L. H. Essery, P. R. Rowntree and J. Smith. 1999. The impact of new land surface physics on the GCM simulation of climate and climate sensitivity. Climate Dyn., 15, 183-203.

Dai, Y.-J. and Q.-C. Zeng. 1997. A land surface model (IAP94) for climate studies, Part I: Formulation and validation in offline experiments. $A d v$. Atmos. Sci., 14, 433-460.

Douville, H., J.-F. Royer and J.-F. Mahfouf. 1995. A new snow parameterization for the Météo-France climate model. Part 1. Validation in standalone experiments. Climate Dyn., 12(1), 21-35.

Essery, R., E. Martin, H. Douville, A. Fernandez and E. Brun. 1998. A comparison of four snow models using observations from an Alpine site. Climate Dyn., 15, 583-593.

Etchevers, P. and 21 others. 2002. Snow MIP, an intercomparison of snow-cover models: first results. In Stevens, J. R., ed. International Snow Science Workshop 2002, 29 September-4 October 2002, Pentiction, British Columbia. Proceedings. Victoria, B.C., B.C. Ministry of Transportation. Snow Avalanche Programs, 353-360.

Fernández, A. 1998. An energy balance model of seasonal snow evolution. Phys. Chem. Earth, 23, 661-666.
Gusev, Ye. M. and O. N. Nasonova. 1998. The land surface parameterization scheme SWAP: description and partial validation. Global Planet. Change, 19, 63-86.

Jin, J., X. Gao, Z.L. Yang and others. 1999. Comparative analyses of physically based snowmelt models for climate simulations. 7. Climate, 12(8), Part 2, 2643-2657.

Jordan, R. 1991. A one-dimensional temperature model for a snow cover: technical documentation for SNTHERM.89. CRREL Spec. Rep. 91-16.

Kondo, J. and T. Yamazaki. 1990. A prediction model for snowmelt, snow surface temperature and freezing depth using a heat balance method. 7. Appl. Meteorol., 29(5), 375-384.

Koren, V., J. Schaake, K. Mitchel, Q.-Y. Duan, F. Chen and J. M. Baker. 1999. A parameterization of snowpack and frozen ground intended for NCEP weather and climate models. F. Geophys. Res., 104, 19,569-19,585.

Lehning, M., P. Bartelt, B. Brown and C. Fierz. 2002. A physical SNOWPACK model for the Swiss avalanche warning service. Part III. Meteorological forcing, thin layer formation and evaluation. Cold Reg. Sci. Technol., 35(3), 169-184.

Lehning, M., P. Bartelt, B. Brown, C. Fierz and P. Satyawali. 2002. A physical SNOWPACK model for the Swiss avalanche warning. Part II. Snow microstructure. Cold Reg. Sci. Technol., 35(3), 147-167.

Niu, G.-Y. and Z.-L. Yang. 2003. The Versatile Integrator of Surface Atmospheric processes (VISA), part 2: evaluation of three topography-based runoff schemes. Global Planet. Change 38, 191-208.

Pyles, R. D., B. C. Weare and K.T. Paw U. 2000. The UCD advanced canopy-atmosphere-soil algorithm: comparisons with observations from different climate and vegetation regimes. Q. F. R. Meteorol. Soc., 126, 2951-2980.

Schlosser, C. A. and 33 others. 2000. Simulations of a boreal grassland hydrology at Valdai, Russia: PILPS 2(d). Mon. Weather Rev., 128(2), 301-321.

Shmakin, A. B. 1998. The updated version of SPONSOR land surface scheme: PILPS-influenced improvements. Global Planet. Change, 19, 4962.

Smirnova, T. G., J. M. Brown and S. G. Benjamin. 2000. Parametrization of cold-season processes in the MAPS landsurface scheme. F. Geophys. Res., 105, 4077-4086.

Strasser, U., P. Etchevers and Y. Lejeune. 2002. Intercomparison of two snow models with different complexity using data from an alpine site. Nord. Hydrol., 33(1), 15-26.

Takata, K. and S. Emori. 1999. Development and validation of a land surface model, "MATSIRO”. Activity Report of GAME-Siberia, 103-106.

Verseghy, D. L. 1991. CLASS - a Canadian land surface scheme for GCMs. I: Soil model. Int. f. Climatol., 11 (1), 111-133.

Xue, Y., P. J. Sellers, J. L. Kinter and J. Shukla. 1991. A simplified biosphere model for global climate studies. 7. Climate, 4, 345-364.

Yamazaki, T. 2001. A one-dimensional land surface model adaptable to intensely cold regions and its applications in Siberia. 7. Meteorol. Soc. Jpn, 79, 1107-1118.

Yang, Z.-L. and G.-Y. Niu. 2003. The versatile integrator of surface and atmospheric processes (VISA), part 1: model description. Global Planet. Change, 38, 175-189. 